تأثير هلام ورقة الصبار على التئام الجروح وتأثيره كمضاد جرثومي

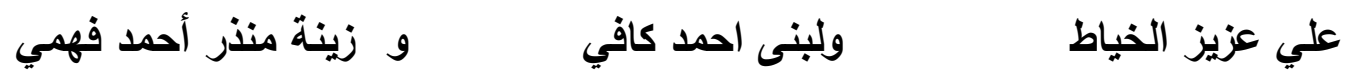

فرع الفسلجة والأدوية - كلية الطب البيطري - جامعة بغداد - العراق ولئه مناف

\title{
الخلاصة
}

اجريت هذه الدراسة لتقييم التأثير العلاجي لهلام أوراق نبات الصبار (Aloe Vera gel) AVG الذهبية (Staphylococcus aureus) والزوائف الزنجارية .(Pseudomonas aeruginosa) حضرت تخافيف قياسية من هذا الهلام تراوحت بين (10 - 100 \% )وأختبرت باستخدام طبق

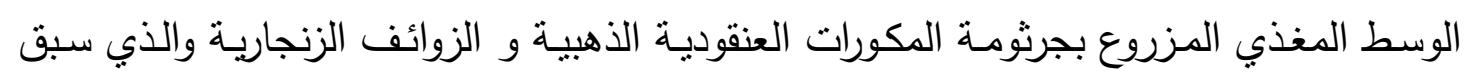
بعمل الفحوصات الزرعية والمجهرية والكيموحيوية.

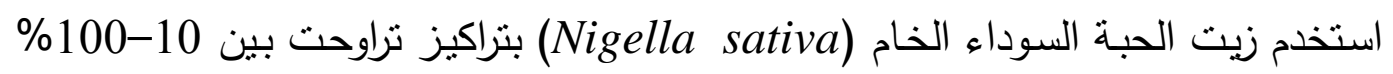

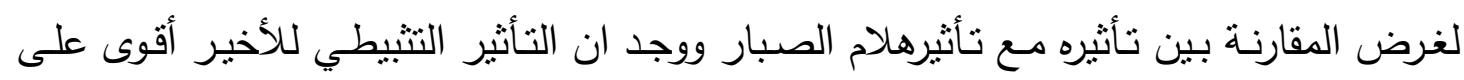

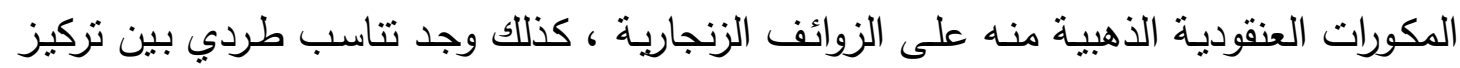

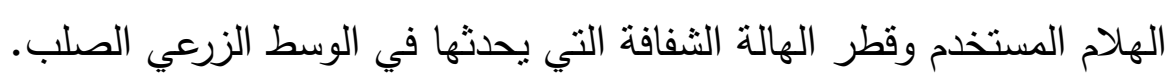

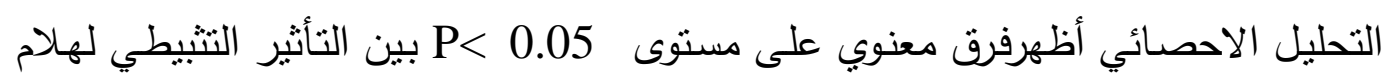
الصبار وزيت الحبة السوداء.

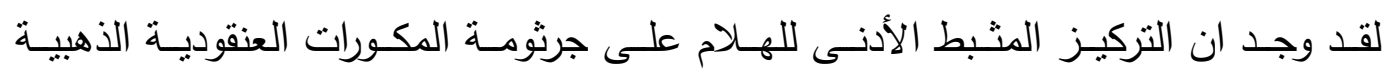
المستخدمة في دراسة تأثير هلام الصبار في الحي على الأرانب هو 60 ملغرام / مليلتر والتركيز القاتل الأدنى هو 80 ملغرام / مليلتر.

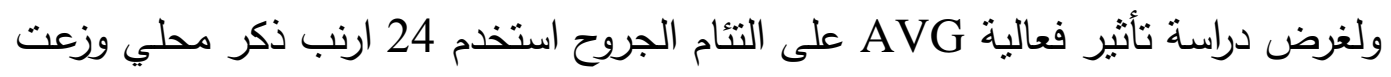

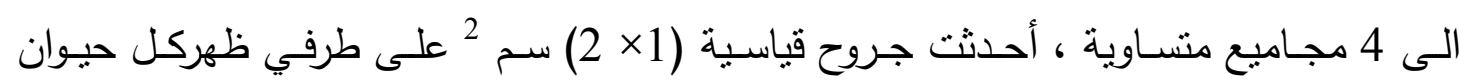
بواسطة مشـرط جراحي ، منلت المجموعـة الأولى السيطرة حيث لم تعـالج لملاحظـة الألثئام

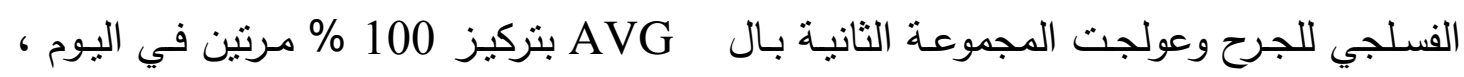

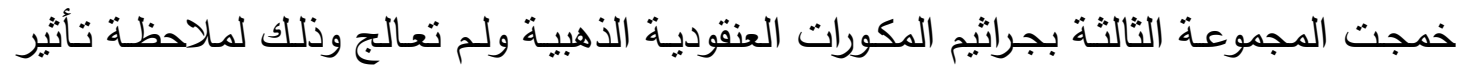
الجهاز الدفاعي للجسم على وجود الخمج و الدجمعة الأخيرة كانت تلك التي خمجت بند 
الجرثومة وعولجت بال AVG لملاحظة التأثير المضاد للجراثيم ،في المجموعتين الثانية والرابعة تركت الجهة الثانبة من الحيوانات كسبطرة ذاتية. تمت المقارنـة بين مجاميع العـلاج ومـع السيطرة والسيطرة الذاتيـة بفترة الالتئام والمظهر العياني للجرح. لغرض دعم نتائج تأثير الـ AVG على التئئام الجروح ، أجريت تجربة ثانية أستخدم فيها

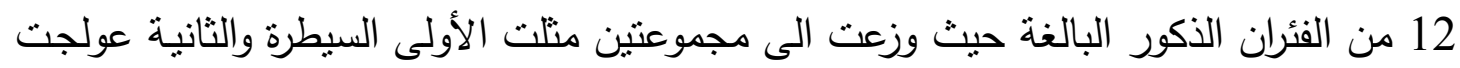

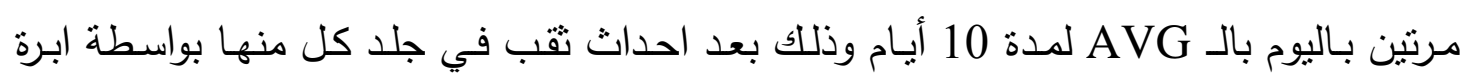

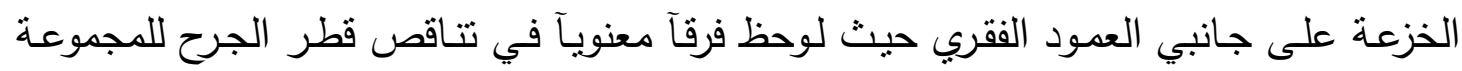

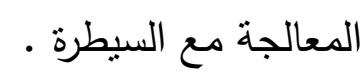

تعد النتائج التي تم الحصول عليها في هذه الدراسة خطوة مهمة في تسليط الضوء على

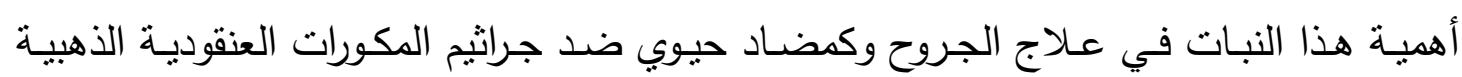
والزوائف الزنجارية. 


\section{The effect of Aloe Vera leaf gel in promoting wound healing and as antibacterial}

\section{Ali Aziz Al-Khayyat, Lubna Ahmed Kafi and Zena Munther A. Fahmi}

Dept. of Physiology and Pharmacology-College of Vet. Med.- Baghdad University -Iraq

\section{Summary}

This study was carried out to explore the effect of Aloe Vera leaf gel in promoting wound healing and to investigate the antibacterial effect against some pathogenic bacteria in comparison with Nigella sativa oil. Standard dilutions of Aloe Vera leaf gel were made from ten to one hundred percent and its antibacterial effect had been examined in seeded agar method against Staphylococcus aureus and Pseudomonas aeruginosa both were previously identified by laboratory and biochemical methods, Nigella Sativa oil which is known to be one of the important medicinal plant was used for comparison. Statistical analysis showed a significant difference $(\mathrm{P}<0.05)$ between AVG and Nigella Sativa oil.

The effect of Aloe Vera leaf gel against Staph .aureus was more potent than against Pseudomonas aeruginosa. There was a proportional relation between different concentrations of AVG with the values of inhibition zones diameters of the bacteria. Results showed that Aloe Vera was more potent than Nigella sativa against both bacteria.

The Minimum Inhibitory Concentration (MIC) was sixty $\mathrm{mg} / \mathrm{ml}$ and the Minimum Bactericidal Concentration (MBC) was eighty $\mathrm{mg} / \mathrm{ml}$ for Staph aureus.

In order to investigate the effect of Aloe Vera gel on wound healing, twenty-four local male rabbits were used. They were divided into four equal groups and each animal was wounded in both sides of the back region by making a one by two centimeter square standard longitudinal incision with surgical scalpel. The first group was a control group (wounded without treatment); this group was employed to observe the normal wound healing. The second group was treated with crude Aloe Vera leaf gel twice daily for 10 days. While the third group was wounded and infected with 
the pathogenic bacteria Staphylococcus vaureus without treatment, in order to observe the natural body defense against pathogenic microorganisms. The last group was infected with the same bacteria but treated with crude Aloe Vera leaf gel to observe the antibacterial effect. The wounds in the left side in second and fourth group were left as self-control.

The treated groups were compared with the control group and the self-control in respect to period of healing and feature through visual observation of changes.

Furthermore, in order to assess the effect of topical Aloe Vera gel in promoting wound healing, twelve adult male mice used; they were divided into two equal groups. A hole was induced in each animal by a biopsy needle; the control group received no treatment while the other group was receiving topical treatment with crude Aloe Vera gel twice daily for ten days.

A significant decrease in wound diameter was noticed in the animals treated with Aloe Vera gel in comparison with the nontreated control group.

From the above-mentioned results, it can be concluded that this study is a good step to show that crude Aloe Vera leaf gel promotes wound healing and has an antibacterial effect in vitro and in vivo against Staphylococcus aureus and Pseudomonas aeruginosa.

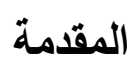

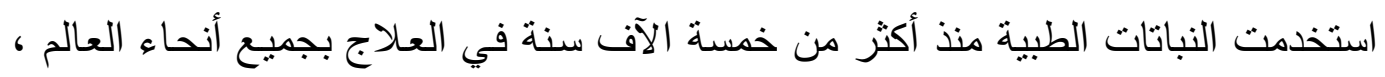

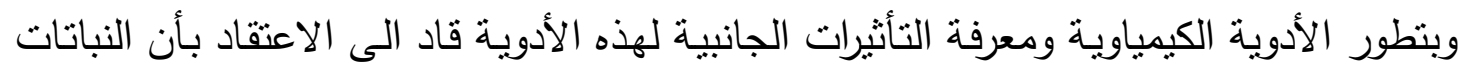

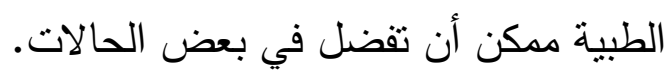

أنشارت (1) الى ان 80 \% من العالم بستخدم النباتات في العلاج بصورة مباشرة او غير

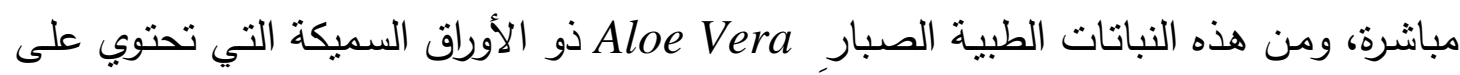

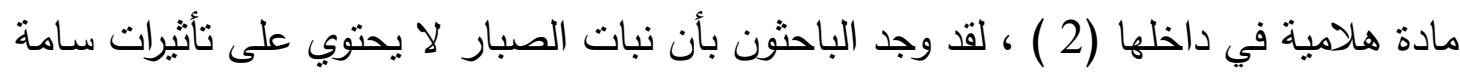

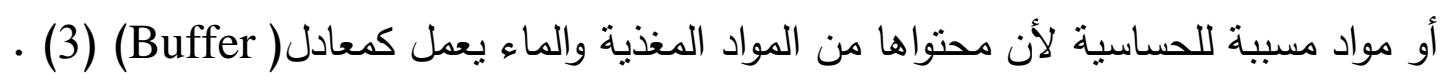

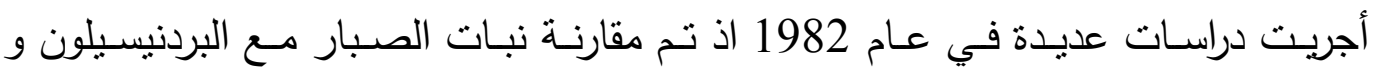
الأندوميثاسين ووجد ان نبـات الصبار اكثر فعالية من هذين الدوائين بدون دراسـة التاثيرات الجانبية والسمية لفترة طويلة (4). 
يوجد حوالي 400 نوع من الصبار تقريباً ولكن هناك 4 انواع فقط مهمة من الناحية الغذائية

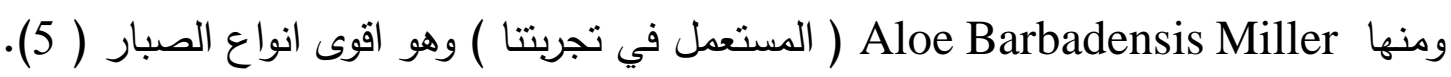
هلام الصبار له عدة خصائص طبية تشمل قدرته على شفاء الجروح والحروق (

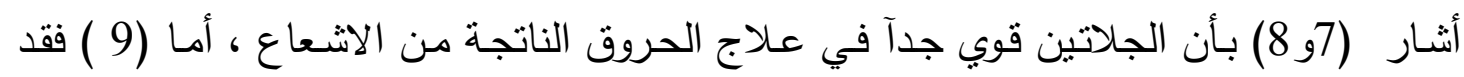

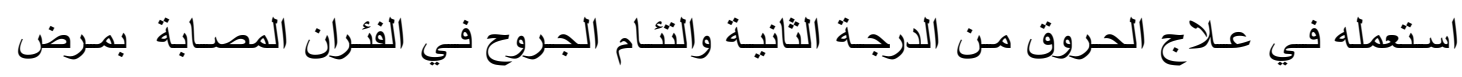
السكري ، كما استعمل هلام نبات الصبار في علاج الحلم المتتققة في ابقار الحليب (10 ).

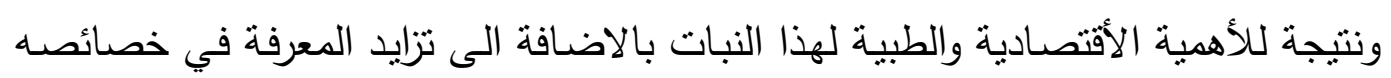

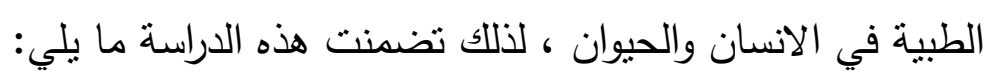
1- استخلاص هلام الصبار من الأوراق.

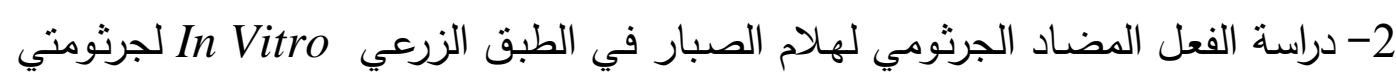

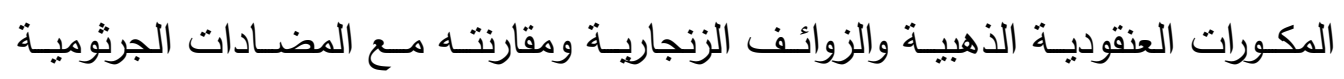
القياسية منل الجنتاميسين ونباتات أخرى منل زيت الحبة السوداء. 3- دراسة تأثيرهلام الصباركمضاد جرثومي في الحي In Vivo على الأرانب. 4- دراسة قابلية هلام الصبار على النتئام الجروح في الفئران.

\section{المواد وطرائق العمل}

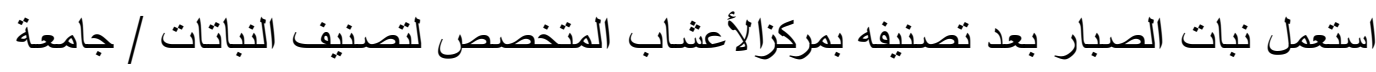
بغداد وقد جمع الهلام حسب الطريقة الموصوفة من قبل (11) وحضرت التراكيز القياسية لهلام

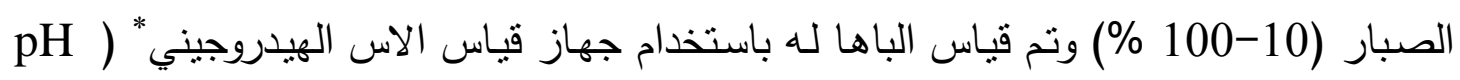

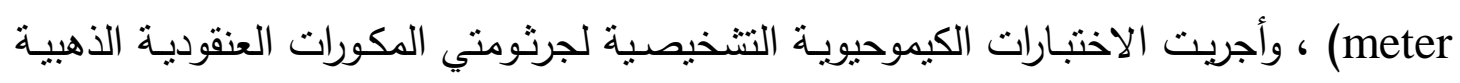

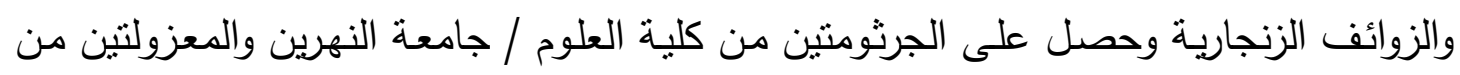
اصـابات جلدية ، ولدراسة الفعل المضاد الجرثومي عمل فحص الحساسية لكلا الجرثومتين

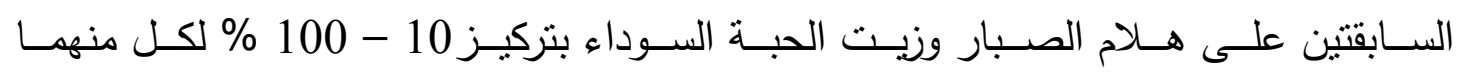
والجنتاميسين بتركيز 30 مايكروغرام/مليلتر في الطبق الزرعي_In Vitro ، واستخدمت طريقة

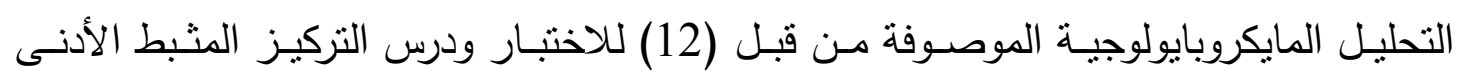
Minimum والتزكيز القاتل الأدنى (MIC Minimum Inhibitory Concentration ) لجراثيم المكورات العنقودية الذهبية المستخدمة في (MBC Bactericidal Concentration 
دراسة نأثير هلام الصبار كمضاد جرثومي في الحي على الأرانب حسب الطريقة الموصوفة من قبل (13).

لدراسة الفعل المضاد الجرثومي لهلام الصبار في الحي على الأرانب ، استخدم 24 أرنب

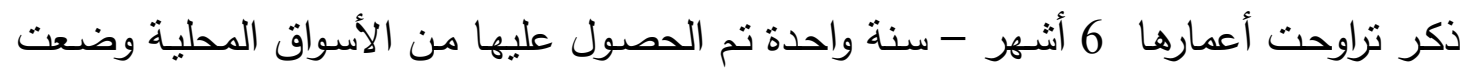

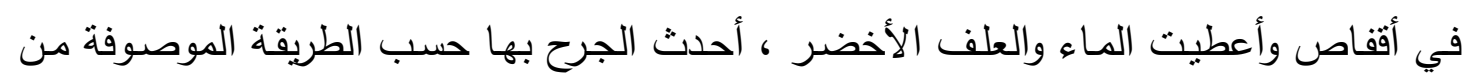

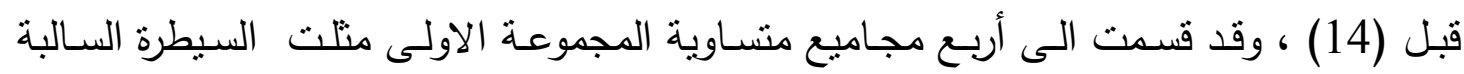

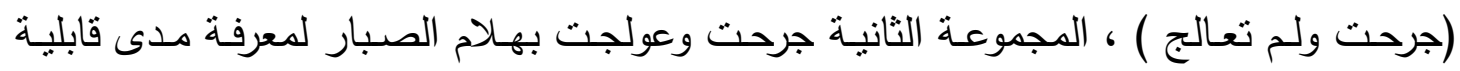

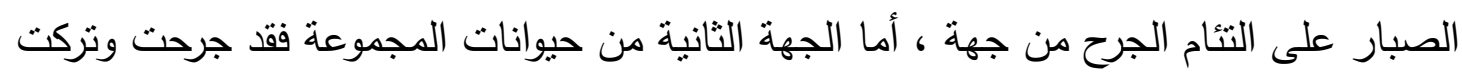
دون علاج كسيطرة ذاتية.

المجموعة الثالثة جرحت وخمجت بجرثومة المكورات العنقودية الذهبية وتركت بدون علاج لمعرفة تطور الاصسابة، أما المجموعة الرابعة فقد جرحت وخمجت بجرثومة وخدة المكورات العنقودية الذهبية وعولجت بهام الصبار بتركيز 100\% من جهة ، أما الجهة الثانية من حيوانات التجربة فقد جرحت وخمجت وتركت بدون علاج كسيطرة ذاتية وفي جميع المجاميع تم ملاحظة التغيرات العيانية التي تحدث للجروح على مدى 12 يوم من احداث الجروح.

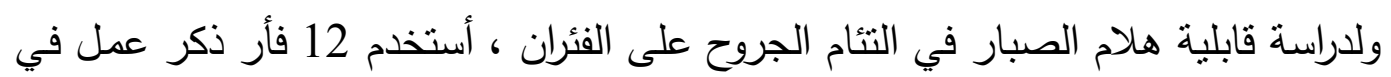

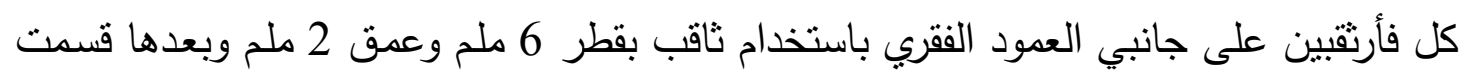

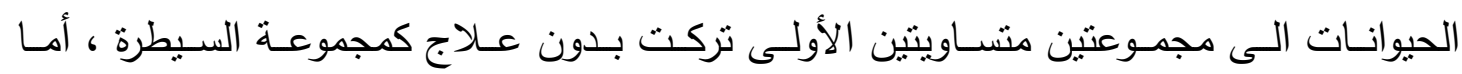
المجموعة الثانية فقد عولجت بهلام الصبار ، وقد درس ثأثير النبات بقياس قطر التقب المعمول

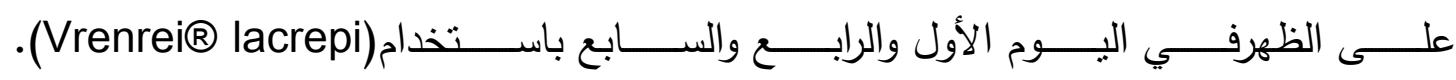

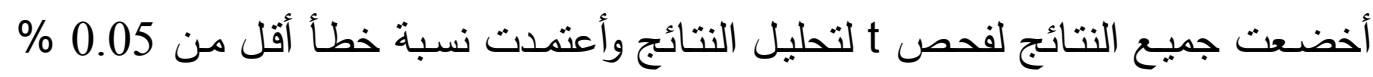
حدآ لقبول النتائج. 


$$
\text { النتائج }
$$

كانت نتائج الفحوصات الكيموحيوبة كما مبين في الجدول (1) جدول (1 ): نتائج الفحوصات الكيموحيوية

\begin{tabular}{|c|c|c|}
\hline الزوائف الزنجارية & المكورات العنقودية & الاختبارات \\
\hline موجب & 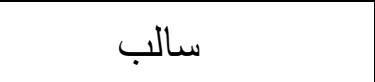 & Oxidase \\
\hline موجب & موجب & Catalase \\
\hline موجب & موجب & Gelatinase \\
\hline أخضر ، منتشر & ذهبي ، موضعي & Pigment Production \\
\hline
\end{tabular}

أظهرت نتائج فحص الحساسية لجرثومتي المكورات العنقوديـة الذهبيـة والزوائف الزنجاريـة لهلام الصبار والجنتاميسين وزيت الحبة السوداء وكما مبين في جدول (3،2، 4) وأعتمد الفرق بين المجاميع على قطر منطقة التثبيط المقاسـة في الطبق،اذ ان هلام الصبار تقوق على زيت الحبة السوداء بتثيطه للجراثيم وان حساسية الجرثومتين المذكورتين تزداد كلما زاد نزكيز الهام. أما حساسية الجرثومتين للجنتاميسيين فقد كانت مقاربة للدراسات التي اجريت من قبل(15 ). أما قياس الاس الهيدروجيني فقد كان 4.5 . 
جدول (2): أقطار مناطق التثبط (ملم) لهلام الصبار وزيت الحبة السوداء ضد جرثومة المكورات العنقودية الذهبية

\begin{tabular}{|c|c|c|}
\hline هلام الصبار & التركيز & 10 \\
\hline b $0.33 \pm 8.33$ & a $0.88 \pm 30.33$ & 20 \\
\hline b $0.33 \pm 9.33$ & a $0.88 \pm 34.66$ & 30 \\
\hline b $0.32 \pm 11.33$ & a $0.88 \pm 36.66$ & 40 \\
\hline b $0.32 \pm 13.33$ & a $0.33 \pm 38.33$ & 50 \\
\hline b $0.32 \pm 15.33$ & a $0.33 \pm 39.33$ & 60 \\
\hline b $0.32 \pm 16.66$ & a $0.32 \pm 40.66$ & 70 \\
\hline b $0.33 \pm 18.33$ & a $0.57 \pm 41.00$ & 80 \\
\hline b $0.32 \pm 20.33$ & a $0.32 \pm 42.66$ & 90 \\
\hline b $0.32 \pm 22.33$ & a $0.88 \pm 43.66$ & 100 \\
\hline b $0.32 \pm 24.33$ & a $0.33 \pm 45.66$ & 30 \\
\hline
\end{tabular}

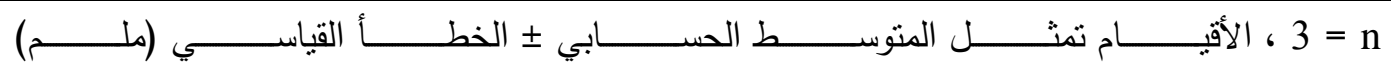
الأحرف المختلفة تعني وجود فرق معنوي بمستوى احتمال أقل من 0.05 \% الافئ جدول (3): أقطار مناطق التثبي (ملم) لهلام الصباروزيت الحبة السوداء ضد ضد جرثئومة الزوائف الزنجارية

\begin{tabular}{|c|c|c|c|}
\hline زيت الحبة السوداء & & هلام الصبار & التركيز \% \\
\hline b $0.33 \pm 7.33$ & a & $0.88 \pm 14.66$ & 10 \\
\hline b $0.32 \pm 9.33$ & a & $0.32 \pm 20.66$ & 20 \\
\hline b $0.32 \pm 10.33$ & a & $0.88 \pm 21.33$ & 30 \\
\hline b $0.32 \pm 12.33$ & a & $0.57 \pm 23.00$ & 40 \\
\hline b $0.57 \pm 13.00$ & a & $0.32 \pm 24.00$ & 50 \\
\hline b $0.32 \pm 14.33$ & a & $0.33 \pm 24.00$ & 60 \\
\hline b $0.33 \pm 16.66$ & a & $0.88 \pm 26.00$ & 70 \\
\hline b $0.33 \pm 18.66$ & a & $0.57 \pm 26.00$ & 80 \\
\hline b $0.33 \pm 20.66$ & a & $0.33 \pm 27.66$ & 90 \\
\hline b $0.33 \pm 22.33$ & a & $0.33 \pm 30.33$ & 100 \\
\hline
\end{tabular}

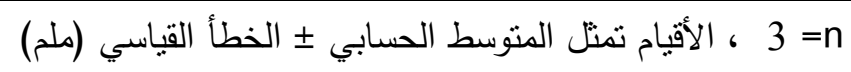

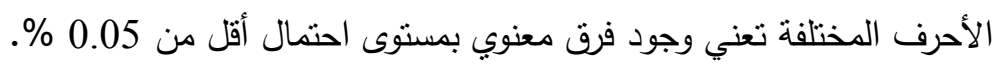




\begin{tabular}{|c|c|c|c|c|}
\hline \multicolumn{5}{|c|}{ جدول (4): حساسية جراثيم الاختبار للجنتاميسين } \\
\hline المنوسط الحسابي 土الخطأ القياسي & & 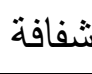 & قطر & جراثيم الاختبار \\
\hline $0.33 \pm 13.66$ & 13 & 14 & 14 & المكورات العنقودية الذهبية \\
\hline $0.33 \pm 14.66$ & 14 & 15 & 15 & الزوائف الزنجارية \\
\hline
\end{tabular}

لقد ظهر أن التركيز المثبط الأدنى لهـام الصبارضــ جرثومـة المكورات العنقوديـة الذهبيـة

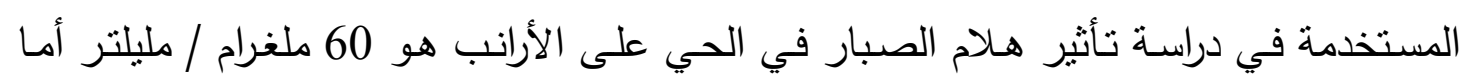
التركيز القاتل الأدنى فقد كان 80 ملغرام / مليلتر .

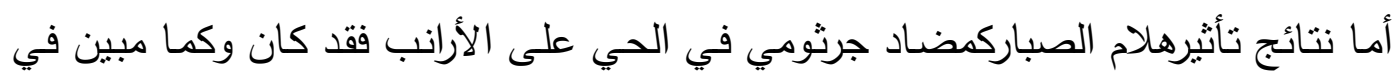

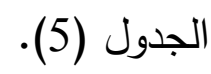


جدول (5): تأثير هلام الصبار كمضاد جرثومي في الحي على الأرانب

\begin{tabular}{|c|c|c|c|c|c|c|c|}
\hline $\begin{array}{l}\overline{3} \\
\text { 章 }\end{array}$ & $\begin{array}{l}\text { 哥 } \\
\text { 告 }\end{array}$ & 雯 & 哥 & $\frac{\overline{3}}{2}$ & $\overline{\bar{a}}$ & 炜 & 离事 \\
\hline \multicolumn{2}{|l|}{ 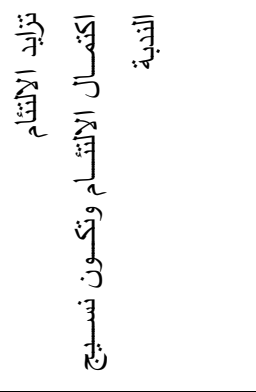 } & 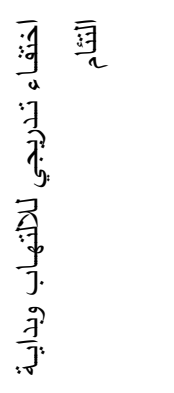 & 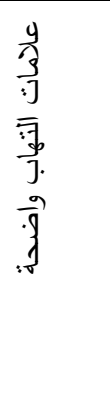 & 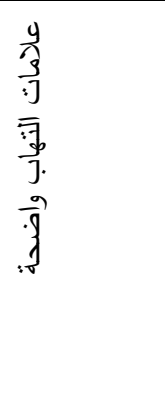 & 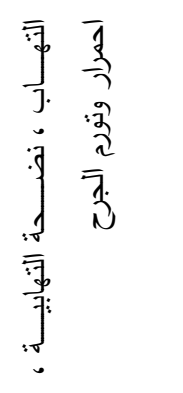 & 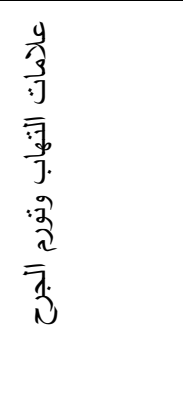 & 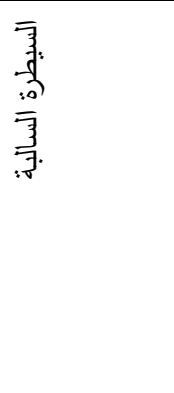 \\
\hline & $\begin{array}{l}\bar{y} \\
\overline{3} \\
\overline{3} \\
\bar{n} \\
\bar{n} \\
\bar{\lambda}\end{array}$ & 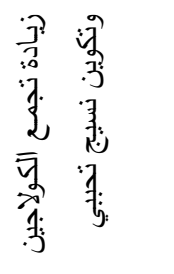 & 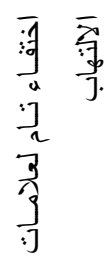 & 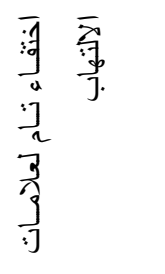 & 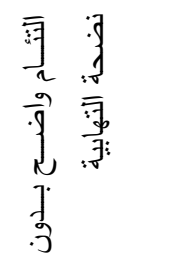 & 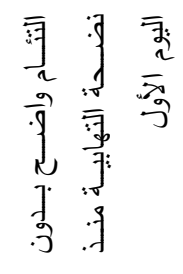 & 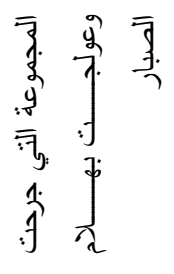 \\
\hline \multirow[t]{2}{*}{ 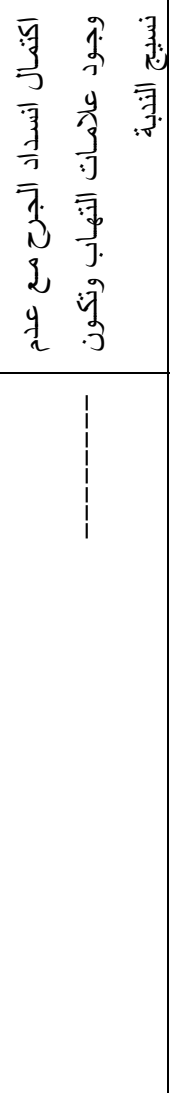 } & 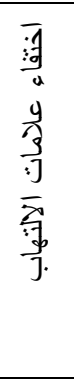 & 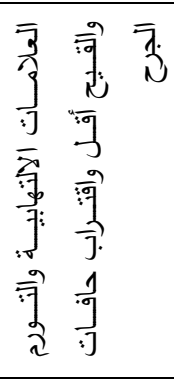 & 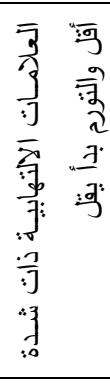 & 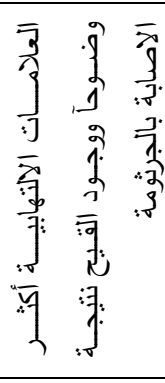 & 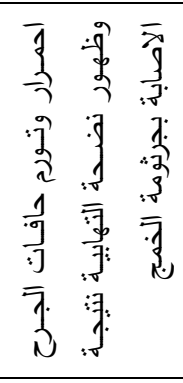 & 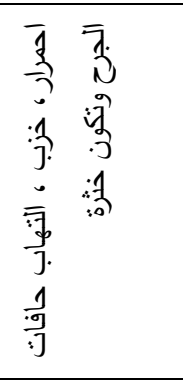 & 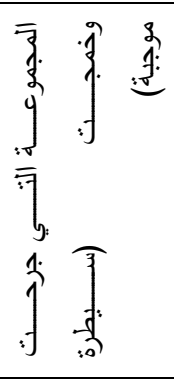 \\
\hline & 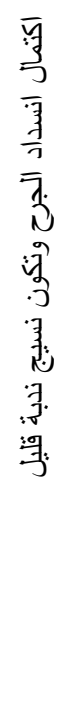 & 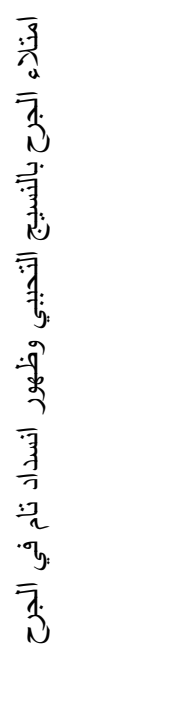 & 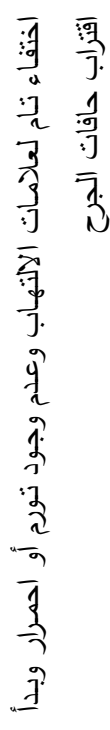 & 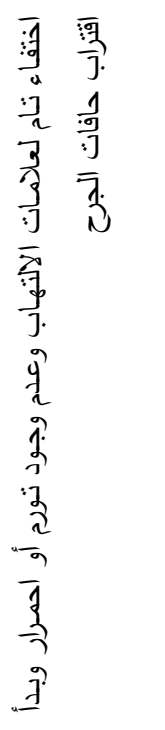 & 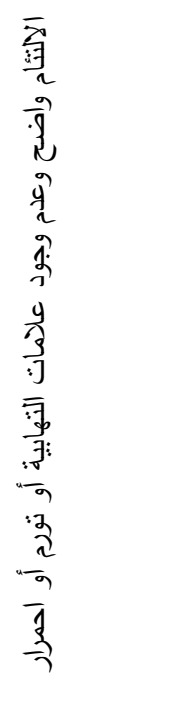 & 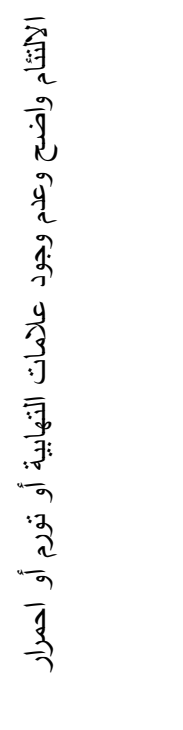 & 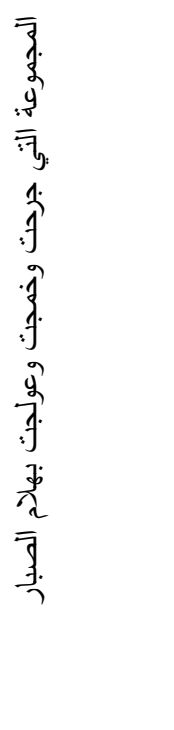 \\
\hline
\end{tabular}


أمـا نتائج دراسـة قابلية هـلام الصبار في التئـام الجروح على الفئران فقد أظهرت النتائج ان

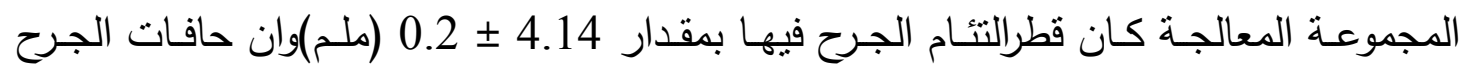
نظيفة وتكون نسيج تحببي، أما المجموعة غير المعالجة فكان قطرالالتئام فيها بمقدار

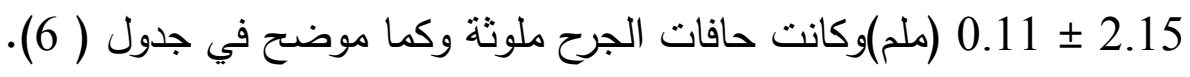

جدول(6):يظهز التأثير الموضعي لهلام الصبار على الجروح في الفئران

\begin{tabular}{|c|c|c|c|c|}
\hline & \multicolumn{3}{|c|}{ نقصان قطر الجرح ( مليلمتر ) } & \\
\hline & \multirow{2}{*}{ اليوم السابع } & \multirow{2}{*}{ اليوم الرابع } & \multirow{2}{*}{ اليوم الأول } & \\
\hline 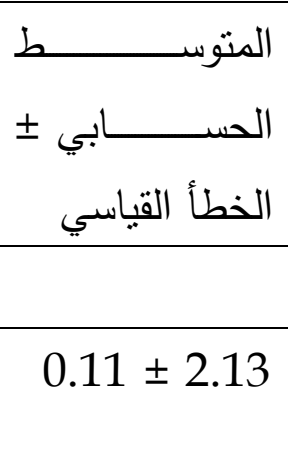 & & & & المعالجة المجوعـــة غــــر \\
\hline $0.20 \pm 4.14$ & 4.5 & 4.2 & 3.8 & لمجموعة المعالجة \\
\hline
\end{tabular}

\section{المناقثة}

هناك العديد من العوامل التي لها دورآ هامآ في التئام الجروح ومنها نوع العلاج المستعمل ،

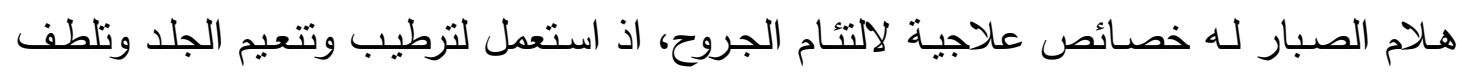

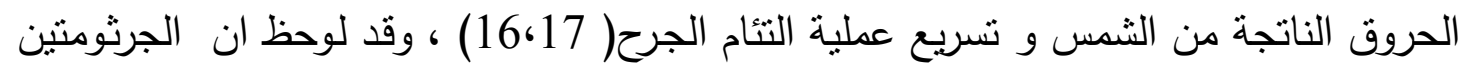
التي استعملت لفحص الحساسية بأنها حساسة لهام الصبار وذللك قد يكون لأحتوائها على مواد

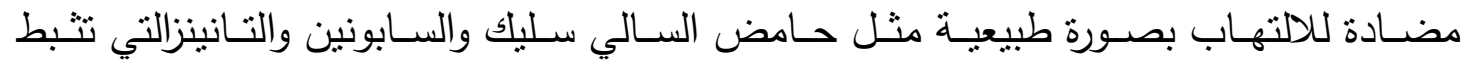

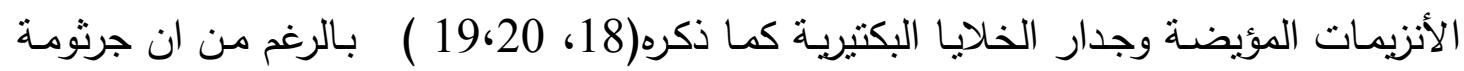
الزوائف كانت أقل حساسية من المكورات العنقودية الذهبية وذللك لاحتواء الزوائف على كبسولة

$$
\text { تقبها من المضادات الحيوية (21). }
$$

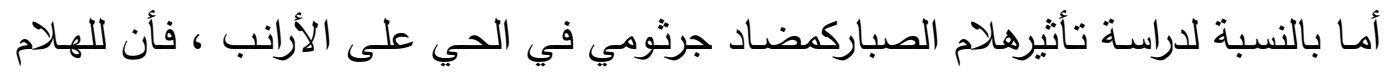

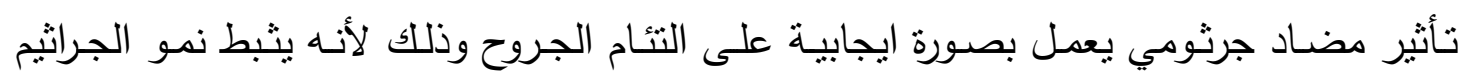

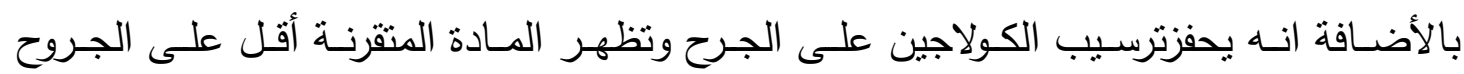

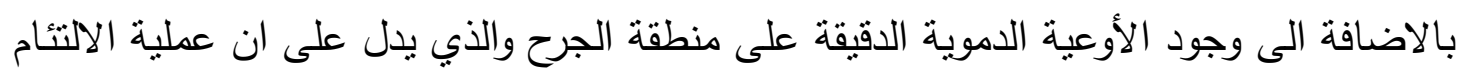

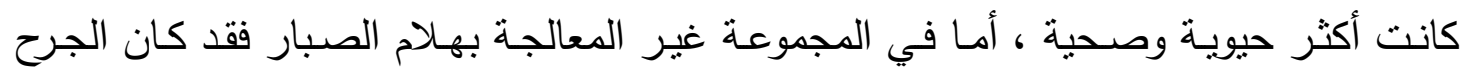


متصلب ومتقرن وذا حافات ملوثة ، ويعود السبب الى ان المجموعة التي تلقت العلاج بهلام الصبار والذي يوفر الأوكسجين ويساعد على تكوين دورات دموية دقيقة والتي تساعد في عملية الالتئام (22) ، بالاضافة الى ان هلام الصبار يحتوي على المواد الضرورية لعملية الالتئام منها

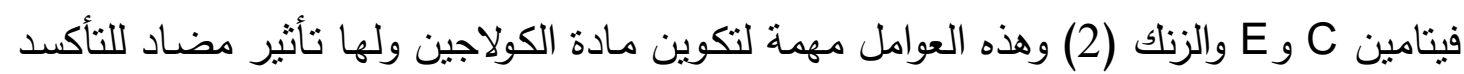

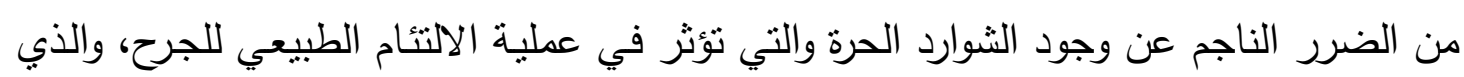

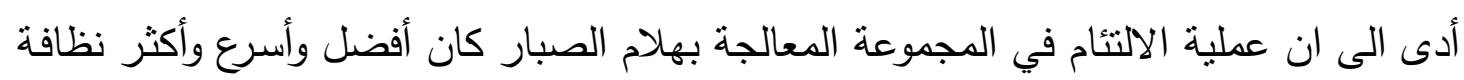
من الجروح غير المعاملة بالهام.

ولنفس العوامل السابقة الذكر التي يساعد على حدوثها استعمال هـلام الصبار كان

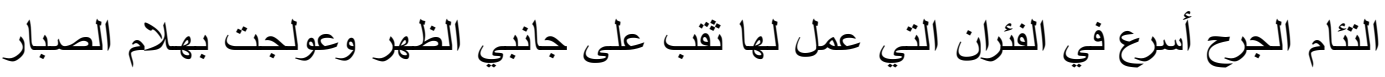
وفرت لها ظروف التئام أفضل من نلاك التي عمل لها نقب ولم يستعمل لها هلام الصبار في العلاج.

\section{المصادر}

1- World Health Organization. (WHO). (1998).Quality control methods of medicinal plant materials. Regional office of the western pacific. Manila.

2- Coats, B.C. (1979). The Silent Healer, A Modern Study of Aloe Vera. Texas, Garland.

3 - Michael, M.T. and Pizzorno, J.E. (1992).An Encyclopedia of Natural Medicine.

4- Murray, F. (1994)."Therapy and Treatment with Aloe Vera." Better Nutrition for Today's Living.117-129.

5- Craig, W. (2001). "The All-Purpose Gel," Vibrant Life. J. Ethnopharmacol; 33(2):150-200.

6- Danhof, I. (1993).Potential Benefits from Orally-ingested Internal Aloe Vera Gel. International Aloe Science Council, Irving (Texas), 10th Annual Aloe Scientific Seminar.

7-Morgan,P.;Hansel,R.;Youngken,H.W.;Smith,M.C.;Roth,R.A.and tter , W .J . (1979). Therapeutic of Aloe Vera Gel. Pharmacology.14 (3):78101. 
8- World Health Organization. (WHO). (2002). Monograph on selected medicinal plants.Vol.2.Geneva.

9- Cowda, K. (1990).CRC Handbook of Ayurvedic Medicinal Plants. Boca Raton: CRC Press.

10- Vazquez, B.; Avila, G.; Segura, D. and Escalanta, B. (1996). Antiinflammatory Activity of Extracts from Aloe Vera gel .J.Ethnopharmacol.55:69-75.

11- Yolanta, S. and Rivka, B. (1994). Aloe Vera gel activity against plant pathogenic fungi. Post harvest Biology and Technology. Vol, 6, p.159165.

12- Al-Khayyat, A.A (1969) Pharmacologic and toxocologic studies with polymyxin B and colistin (Polymyxin E). MSc. Thesis. Cornell University. New York. USA.

13- Al-Saloos, A.T. (1995). Study the chemical and pharmacological properties for Thymus. MSc. Thesis. Pharmacology and Toxicology department / College of Veterinary Medicine. University of Baghdad.

14- Al-Sammak, A.M. (2001).A study of antimicrobial effect of oil extract of black seed (Nigella sativa linn.) on some pathogenic microorganisms that is isolated from clinical pathogenic cases. Msc. Thesis. College of Veterinary Medicine. University of Baghdad.

15- World Health Organization. (WHO). (1994). Sensible guide to the use of antibiotics. Prentice Hall. New Jersey.

16- Singh, M.; Scharma, J.N.; Arora, R.B., and Kocher, B.R. (1973). "Beneficial Effect of Aloe Vera in the Healing of Thermal Burns and Radiation Injury in Albino Rats." Indian Journal of Pharmacy, Vol. 5, p. 258.

17- Rund, C. (1996). Non-conventional Topical Therapies for Wound Care. Ostomy/Wound Management, $\underline{42}$, (5), pp. 18-26.

18- Tyler, E.V.; Speediae, M.K., and Robbers, J.E. (1996). Partial Purification and Some Properties of an Antibacterial Compound from Aloe vera. Phytotherapy Res.2:67-69.

19- Urch, D. (1999). Aloe vera the Plant Nutrients Gift. Backdown publications, Bristol. United Kingdom. P.8-17 
20- Valerie, A.F.; Bradburg, F.; Pamela, C.; Eisin, S.; Rhman; Sabita, R. and William, H.S. (2003). In vitro Susceptibility of Shigella flexneri and Streptococcus pyogenes to Inner Gel of Aloe barbadensis miller. Antimicrobial agents and chemotherapy. P.1137-1139.

21- Robert, C; Duguid, J.P and Swain, R.H.(1974). Medical Microbiology, $12^{\text {th }}$. Ed. Vo.1. Longman Group Limited England.

22- Bouchey,R and Gjerstad, Q.(1994). Chemical studies of Aloe Vera. Postgraduate Medical Journal.65:216-217. 